Saudi Journal of Medical and Pharmaceutical Sciences

Abbreviated Key Title: Saudi J Med Pharm Sci

ISSN 2413-4929 (Print) |ISSN 2413-4910 (Online)

Scholars Middle East Publishers, Dubai, United Arab Emirates

Journal homepage: https://saudijournals.com

Review Article

\title{
Effects of Different Types of Microbes on Blood Cells, Current Perspectives and Future Directions
}

Muhammad Sohail ${ }^{1}$, Afsheen Rafiq ${ }^{2}$, Muhammad Naeem ${ }^{1}$, Adnan Shahid ${ }^{1 *}$, Habib ur Rehman ${ }^{3}$, Muhammad Usama Saeed $^{4}$, Muhammad Izhar ${ }^{5}$

${ }^{1}$ Institute of Microbiology, University of Agriculture Faisalabad, Faisalabad, Punjab, Pakistan

${ }^{2}$ Department of Biosciences, COMSATS University, Islamabad, Pakistan

${ }^{3}$ Department of Microbiology, Government College University, Faisalabad, Pakistan

${ }^{4}$ Institute of Biochemistry and Biotechnology, Arid Agriculture University, Rawalpindi, Pakistan

${ }^{5}$ Department of Zoology, Government College University, Faisalabad, Pakistan

DOI: $10.36348 /$ sjmps.2021.v07i01.001 $\quad$ | Received: 19.11.2020 | Accepted: 02.12.2020 | Published: 05.01 .2021

*Corresponding author: Adnan Shahid

\section{Abstract}

Staphylococcus aureus is a dangerous human pathogen and one of the leading causes of infections worldwide While $S$. aureus toxin production is highly strain-specific, because most toxins of $S$. aureus. Some of the genetic diseases that directly associated to the lysis of the cells of the blood. One of the diseases that associated to the genetic level included the sickle cell anemia. This is particularly useful in classifying streptococcal species. A substance that causes hemolysis is a hemolysin. Different effects appeared due to more hemolysis of the cells of the blood by different microbes. $\beta$ Hemolytic streptococci are also detected in laboratory rats but rarely cause disease. Streptococcus pneumoniae and a group of oral streptococci as Streptococcus viridans or viridans streptococci display alpha hemolysis. This is sometimes called green hemolysis because of the color change in the agar. Bacteria are often divided into different families and groups. This division is based in part on the physical appearance of the bacteria as well as some of their chemical and biological characteristics. The organism does not induce hemolysis, the agar under and around the colony is unchanged, and the organism is called non-hemolytic or said to display gamma hemolysis ( $\gamma$-hemolysis).

Keywords: Microbes, Gram positive, Microbial studies, Blood cells, Hemolysis.

Copyright (C) 2021 The Author(s): This is an open-access article distributed under the terms of the Creative Commons Attribution 4.0 International License (CC BY-NC 4.0) which permits unrestricted use, distribution, and reproduction in any medium for non-commercial use provided the original author and source are credited.

\section{INTRODUCTION}

Medical important microbes which present in the different species of the bacteria. This is particularly useful in classifying streptococcal species. A substance that causes hemolysis is a hemolysin. If there more bacteria in diet, it leads to the toxicity which has been studied in the species of mammals as in the dogs. The study of the poisoning associated with excess of bacteria that causes hemolysis has been demonstrated. The excess concentration of bacteria leads to changes in the cells of blood causes breakdown the erythrocytes. Ultimately causes the type of anemia called hemolytic anemia [1].

Some of the genetic diseases that directly associated to the lysis of the cells of the blood. One of the diseases that associated to the genetic level included the sickle cell anemia. This disease occured at the level of genes in which certain types of the mutations occurs abnormally that ultimately leads to the severe defect to the gene. In this type of the disease, cells of the RBCs ultimately become sickle. It affected the overall process of the flow of the blood to the various parts of the body. The main reason caused these abnormal type of the cells or sickle cell would block the path of the blood veins. Due to blockaging of the abnormal cells, blood cannot flow the various parts of the body. It also affected to the overall process of the supply of the oxygen. Less supply of the oxygen is in this type of the disease and more of the breakdown of the cells occurs and ultimately more of the hemolysis $[2,3]$.

$\beta$-Hemolytic streptococci are also detected in laboratory rats but rarely cause disease. $\beta$-Hemolytic streptococci are divided into groups based on Lancefield antigens, with Lancefield groups B and G most commonly isolated from rats. Some of these organisms have been used in experimental infections in rats, but only once have they been associated with naturally occurring disease [4].

Some of the treatments with medical important enzymes such as streptokinase applied in the dogs 
Muhammad Sohail et al., Saudi J Med Pharm Sci, Jan, 2021; 7(1): 1-6

showed that there is less breaking of the RBCs because onions contains the flavonoids that reduces the rate of the lysis of the cells of the blood. Some other studies in vitro also showed that antioxidants that helpful to treat the harmful chemicals that are abnormally produced and randomly inhibited the reaction of the body. These free radicals also inhibited the biocatalysts that actually the enzymes of the body. More concentrations of the free radicals and less concentrations of the antioxidants leads to reactions that also causes the lysis of the RBCs. It ultimately leads to the toxicity of the cells of the blood. There are some other in vitro studies showed that increases of the concentrations of the antioxidants ultimately leads finally to the remove the free radicals that damages of the cells of the body [5].
Some studies about the hemolysis showed that medicines, infections from bacteria, associated with genetic level might the overall cause of the lysis of the cells of the blood. While the comparison of these causes, then rapidly actions against cells of the blood occurs due to the using of the chemicals as well as medicines. While the infections from bacteria, parasites as well as disease associated with autoimmune have least actions while in comparison to the using of the medicines. Some studies also shows evidences against the hemolysis caused by the infections coming from the saliva. High or extreme dose used in such conditions that patients under the medical or taken the chemicals to treat the diseases, then chances of the lysis increases significantly that would also the affected the other reaction in the partially affected cells of the body [6-8].

\section{Role of Microbes in hemolysis}

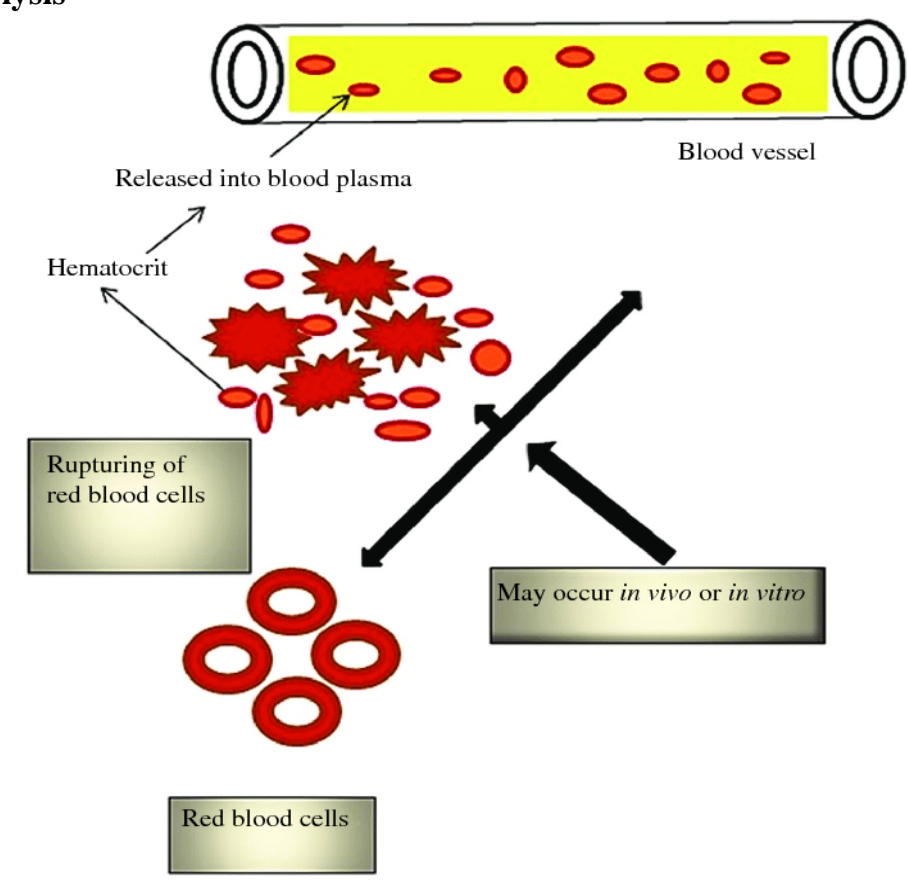

Fig-1: Shows the effect of hemolysis on the blood cells

Different effects appeared due to more hemolysis of the cells of the blood by different microbes. It depends on the certain conditions such as patients under the treatment for treating the diseases associated with rapidly growth of the cells such as cancer. When nonfunctional of the hemoglobin released into the blood and finally to the different fluids of the body. Then the chances effectively increases to the different parts of the body. The concentrations as well as doses of the drugs directly concerted and affected to lysis of the cells. Previous research in the laboratory investigated the breakdown of the cells of the RBCs also showed that different cells of the body that essential and key part of the body affected by the severe product of the hemolysis. As harmful product such as nonfunctional hemoglobin becomes releases to the different parts, it then affected to the various part of the body by creating infections [9].
Several studies about the different contents of the medicinal plants that makes it more useful plant that used as a cooking as well as to treat the disease that are associate with metabolism. Once the disturbance occurs to cells of the body due to toxicity of the microbes , then defense proteins in the onions effectively active to fight and control level of toxicity with no disturbance of the other normal reaction of the body. This toxicity mainly due to the microbes also caused the damages to the organs of the body such a liver and kidney. Severe damage that would occurs in the specific part of the cells of the kidney as well as the cells that are involved in making the proteins for the formation of the clotting, defense, structural as well as some of the proteins that utilized by the cells of the body in catalyzing the reactions to carry as well as maintenance of the metabolism. It showed that some the benefits of the onions due to the higher amount of the compounds that shows activity against the oxidant while in some of the 
Muhammad Sohail et al., Saudi J Med Pharm Sci, Jan, 2021; 7(1): 1-6

studies proves its harmful effects on the body by using them in the concentrations as compared to the normal level [10].

\section{Microbial Alpha hemolysis}

When alpha hemolysis ( $\alpha$-hemolysis) is present, the agar under the colony is dark and greenish. Streptococcus pneumoniae and a group of oral streptococci as Streptococcus viridans or viridans streptococci display alpha hemolysis. This is sometimes called green hemolysis because of the color change in the agar. Other synonymous terms are incomplete hemolysis and partial hemolysis. Alpha hemolysis is caused by hydrogen peroxide produced by the bacterium, oxidizing hemoglobin producing the green oxidized derivative methemoglobin [11].

\section{Microbial Beta hemolysis}

Bacteria are often divided into different families and groups. This division is based in part on the physical appearance of the bacteria as well as some of their chemical and biological characteristics. Betahemolytic strep describe bacteria which all can destroy red blood cells under certain conditions and can cause a variety of different diseases. Streptococcus bacteria are gram-positive, which means that they have an outer wall which can react with certain kinds of dyes and are facultatively anerobic, which means that they can grow without oxygen if necessary. Streptococci are divided into different groups based on the proteins which are found on the bacteria's surface. Staphylococcus aureus is a common class of bacteria. Justly so, S. aureus has been commonly treated with the first and most common class of antibiotic drugs, the penicillins. This is the nonspecific killing of blood cells by metabolic byproducts of bacteria. This can be seen on a blood agar plate, when the blood surrounding the confluent part of your streak turns green, but there is no change around single colonies. Hemedigestion is seen with the choleracausing bacteria, Vibrio cholera [12, 13].

\section{Gamma Hemolysis}

If an organism does not induce hemolysis, the agar under and around the colony is unchanged, and the organism is called non-hemolytic or said to display gamma hemolysis ( $\gamma$-hemolysis). Enterococcus faecalis (formerly called "Group D Strep"), Staphylococcus saprophyticus, and Staphylococcus epidermidis display gamma hemolysis $[14,15]$.

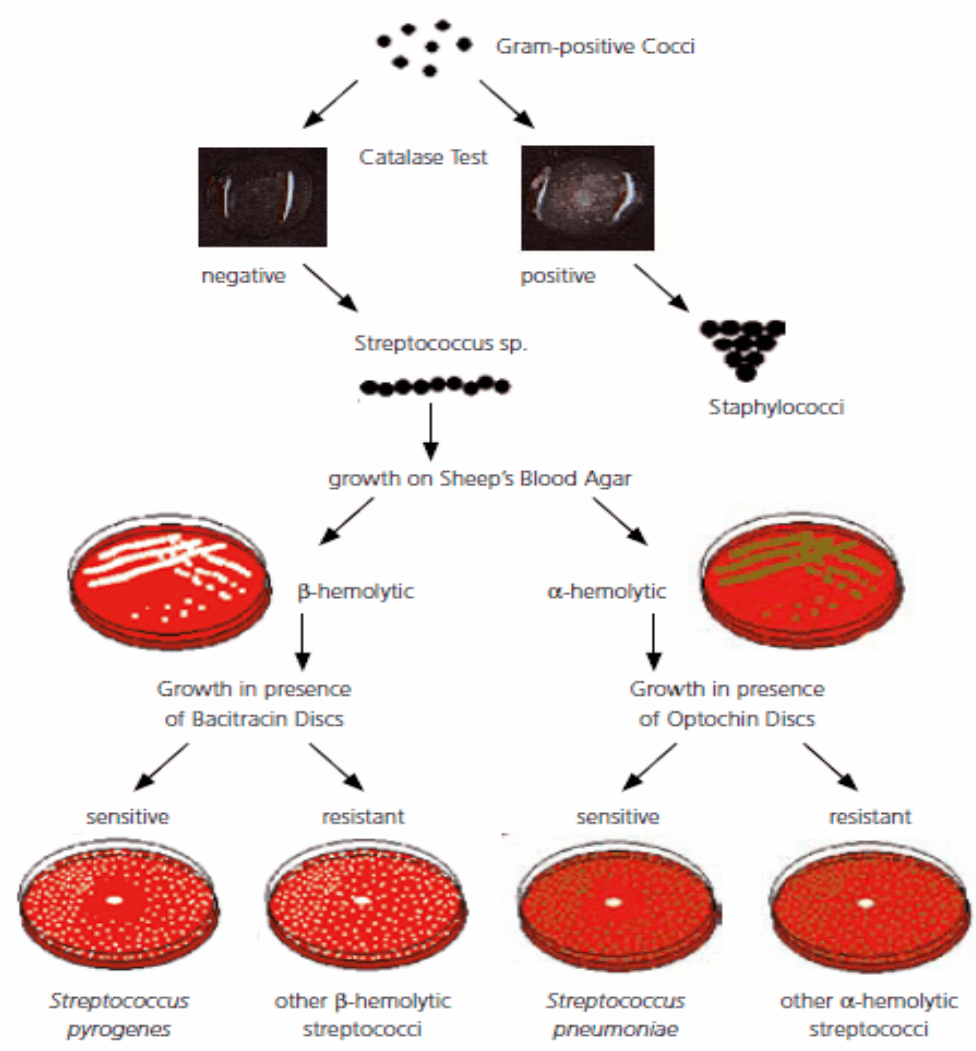

Fig-2: Shows the types of hemolysis by microbes with respect to the blood cells

\section{Toxicity and effects of Microbes}

Poisoning in the dogs caused by the excess of the microbes showed the high level of the toxicity. Certain compounds in onions such as the flavonoids that involved in inhibiting the growth of the bacteria, as well as viruses leads to high toxicity to the cells of the living system. In one way, flavonoids showing the benefits by working against the free radicals and on the other way, it would also causes the inhibition of the enzymes that playing effective role in the reactions 
Muhammad Sohail et al., Saudi J Med Pharm Sci, Jan, 2021; 7(1): 1-6

needed for the growth of the body. The harmful compounds when exceeding the normal level or limit, then these acting as the severe chemicals called the inhibitors that functions in the body to inhibit the growth of the specific and reactions that mandatory for the metabolism. It also effective and useful way to understand the mechanisms of the compounds present in the onions that might the causes of the toxicity to the particular cells of the liver as experiments investigation in the past in the dogs $[16,17]$.

Animals widely used for the purpose of the research in the laboratories as well as in the research institutes because they helpful for the detecting the infections that acre caused by the bacteria as well as the bacteria or other type of the severer infections. In any way, mammals useful for research in the laboratories for carrying the investigation of the vaccine that are useful to treat as well as control the disease in specific effective conditions. Some experiments in the history of the investigation the disease caused either the viruses as well as the bacteria, mammals such as the rats that are used in the in the laboratories, some of the other animals such as dogs as well as the rabbits. The scientists in the past would use them for the discovery of the new virus as well as new bacteria as these mammals also shows many of the characters similar to the human $[18,19]$.

Previous data bout the toxicity caused by microbes showed that the causes of the hemolysis of the cells of the blood included the attacking of the microbial parasites. The main harmful and attacking parasite to the cells of the blood mainly the plasmodium. When the parasites increases in the concentrations or has high level, then it has great chances to break the cells of the blood then ultimately more of the lysis occurs effectively in the blood and agglutination of the RBCs occurs. When this parasite enters into the body through the blood, it directly attack on the cells of the liver which is the major organ in which the all synthesis of the proteins normally occurs for carrying the normal reactions as well as for the metabolic machinery to the building of the body. The cells of the blood would breakdown by the attack of the parasite depends on the concentration of the parasite as well as the pathogenicity. When the parasites increases at the extreme level then then it has great chances to completely break the all cells of the that are RBCs of the blood then ultimately more of the lysis occurs effectively in the blood and agglutination of the RBCs occurs. All these reaction resulted the immune response from the body [20].

Main caused by microbes due to breaking of the cells of the body also causes the major events such lysis of the RBCs. It might due to the many of the causes that significant in breaking the cells of the RBCs. One reason included the medically use, overdose of the chemicals that especially used to treat the diseases such as the hepatitis or other purposes. The chemicals that used to treat the diseases when in the amount exceeding the excess the normal, then these chemicals ultimately attacks to the cells of the blood especially the RBCs. This lysis occured extremely in vivo. The study that based laboratory investigated and experiments based either through the scientists as well as research for carrying the research to analyze the presence of any fluid by investigating them reactions of the outside of the body, then it criticality becomes in vitro research study [21, 22].

Anemia, a type of blood related disorders caused by microbes that causes the inhibition of the oxygen to the RBCs and these cells not working with less amount of the oxygen in the body as well as in the environment. RBCs as a the part of the cells of the blood carrying the gas called oxygen from the component of the environment such as the air and properly supplies to the lungs that are mandatory part to live for the breathing. If there more the compounds in the inner part of the onions showing the benefits by working against the free radicals and on the other way, it would also causes the inhibition of the enzymes that playing effective role in the reactions needed for the growth of the body. Death of the RBCs occurs when less supply of the oxygen which ultimately leads towards the breakdown of the RBCs. Also starting the reactions in the blood that cause the other severe type of the disease $[23,25,26]$.

The lysis also caused by microbes depends on doses applying under different medical conditions caused by microbes [27, 28]. The lysis of the particular type of the blood cells that caused by microbes significantly making the large compositions of the blood increases effectively by using the medicine or other types of the chemicals that can be inhibitory to the other enzymes of the body that are working under the normal conditions [29]. The concentrations as well as doses of the drugs directly concerted and affected to lysis of the cells. High or extreme dose uses in such conditions that patients under the medical or taken the chemicals to treat the diseases increased the chances of the lysis significantly that also the affected the other reaction in the partially affected cells of the body [30, 31]. Low as well as minor concentrations of the chemicals uses that affected the process of the lysis in a minor or little bit. But medium potency levels of the doses uses in such conditions that patients under the medical or taken the chemicals to treat the diseases, then chances of the lysis increase significantly that would also the affect the other reaction in the partially cells of the body $[32,33]$.

The hemolytic activity of the plant extract remains unclear and not completely studied yet caused by microbes. Different factors are involved in 
Muhammad Sohail et al., Saudi J Med Pharm Sci, Jan, 2021; 7(1): 1-6

hemolysis of the cells of blood. Different compounds in medicinal plants inhibited the hemolysis caused by microbes. The further study needed to understand the nature of different chemical compounds in food that responsible for hemolytic activity for the mechanism of inhibition of hemolysis caused by microbes [34-36].

\section{CONCLUSION}

Staphylococcus aureus is a dangerous human pathogen and one of the leading causes of infections worldwide While $\mathrm{S}$. aureus toxin production is highly strain-specific, because most toxins of S. aureus are encoded on mobile genetic elements, some selected toxins such as $\alpha$-toxin and the recently discovered phenol-soluble modulins (PSMs) are encoded on the S. aureus core genome and produced by virtually all $\mathrm{S}$. aureus strains.

\section{REFERENCES}

1. Neter, E. (1956). Bacterial hemagglutination and hemolysis. Bacteriological Reviews, 20(3), 166.

2. Harington, J. S., Miller, K., \& Macnab, G. (1971). Hemolysis by asbestos. Environmental Research, 4(2), 95-117.

3. Blackshear Jr, P. L., Dorman, F. D., \& Steinbach, J. H. (1965). Some mechanical effects that influence hemolysis.

4. Kinosita, K., \& Tsong, T. T. (1977). Hemolysis of human erythrocytes by transient electric field. Proceedings of the National Academy of Sciences, 74(5), 1923-1927.

5. Fischer, D., Li, Y., Ahlemeyer, B., Krieglstein, J., \& Kissel, T. (2003). In vitro cytotoxicity testing of polycations: influence of polymer structure on cell viability and hemolysis. Biomaterials, 24(7), 1121-1131.

6. Blackshear Jr, P. L., Dorman, F. D., Steinbach, J. H., Maybach, E. J., Singh, A., \& Collingham, R. E. (1966). Shear, wall interaction and hemolysis. Asaio Journal, 12(1), 113-120.

7. Kinosita Jr, K., \& Tsong, T. Y. (1977). Voltageinduced pore formation and hemolysis of human erythrocytes. Biochimica et Biophysica Acta (BBA)-Biomembranes, 471(2), 227-242.

8. Usman, G., Muhammad, N., Hamza, R., Usman, I., Ayesha, A., Saqib, U., ... \& Fatima, Q. (2019). A Novel Approach towards Nutraceuticals and Biomedical Applications. Scholars International Journal of Biochemistry, 2(10), 245-252.

9. Ahsan, M., Aslam, M., Akhtar, M. A., Azmi, U. R., Naeem, M., Murtaza, G., ... \& Shafiq, S. (2019). Effect of inoculation of three rhizobial strains on maize hybrids. Journal of Biodiversity and Environmental Sciences, 14(6), 168-177.

10. Naeem, A., Saddique, S., \& Chand, S. A. (2019). Advancement and Future Directions towards Herbal Treatment for Various Diseases.

11. Naeem, M., Hussain, A., Azmi, U. R., Maqsood, S., Imtiaz, U., Ali, H., ... \& Ghani, U. (2019).
Comparative Anatomical Studies of Epidermis with Different Stomatal Patterns in Some Selected Plants Using Compound Light Microscopy. International Journal of Scientific and Research Publications, 9(10), 375-380.

12. Naeem, M., Ashraf, A., Safdar, H. M. Z., Khan, M. Q., Rehman, S. U., Iqbal, R., ... \& Ahmad, G. Biochemical changes in patients with chronic kidney failure in relation to complete blood count and anemia.

13. Hussain, A., Rafeeq, H., Asghar, A., Ullah, S., Imtiaz, U., Ullah, H., ... \& Ilyas, M. D. Combined inhibitory potential of Ammonium thiosulphate and 2-chloro-6-(trichloromethyl) pyridine on ureases activities.

14. Muhammad, N., Muhammad, M., Asim, U., Siraj, A., Ghafoor, A., Jabir, A., Sayed, J. R. Z., Muhammad, Z. H., Tania, Z., \& Irfan, K. (2019). New trends in removing toxic metals from drinking and wastewater by biomass materials and advanced membrane technologies. J Bio Env Sci. 15(3), 10-17.

15. Rafeeq, H., Arshad, M. A., Amjad, S. F., Ullah, M. H., Muhammad, H., Imran, R. K., ... \& Ajmal, H. Effect of Nickel on Different Physiological Parameters of Raphanus Sativus.

16. Rafeeq, H., Tanvir, K., Khan, M. A. B., Basit, I., Ul, Q., Ain, F. F., ... \& Siddique, S. An Effective Approach towards Heavy Metals and their Effects on Different Organs of the Body.

17. Hussain, A., Nashat, N., Liaqat, A., Waheed, M., Aslam, M., \& Asif, N. (2020). A Comprehensive Review on Diabetic Retinopathy and Mental Disorders. IOSR Journal of Biotechnology and Biochemistry. 6(3), 38-51.

18. Salman, M., Saba, Q., Asim, H., Asma, A., Rubab, S., Sara, Z., \& Noman, N. (2020). Antifungal Properties of Copper Nanoparticles against Aspergillus niger. Scholars International Journal of Biochemistry, 3(4): 87-91.

19. Ahmad, I., Khan, S., Naeem, M., Hayat, M., Azmi, U. R., Ahmed, S., ... \& Irfan, M. (2019). Molecular Identification of Ten Palm Species using DNA Fingerprinting. Int. J. Pure App. Biosci, 7(1), 46-51.

20. Rafeeq, H., Ahmad, S., Tareen, M. B. K., Shahzad, K. A., Bashir, A., Jabeen, R., ... \& Shehzadi, I. (2020). Biochemistry of Fat Soluble Vitamins, Sources, Biochemical Functions and Toxicity. Scholars International Journal of Biochemistry.

21. Rafeeq, H., Ahmad, S., Tareen, M. B. K., Shahzad, K. A., Bashir, A., Jabeen, R., ... \& Shehzadi, I. Biochemistry of Fat Soluble Vitamins, Sources, Biochemical Functions and Toxicity.

22. Naeem, M., Ali, J., Hassan, M. Z., Arshad, B., Rao, M. H. I., Sarmad, M. S. K., ... \& Hussain, M. U. Novel Approach towards DNA Barcoding as a 
Muhammad Sohail et al., Saudi J Med Pharm Sci, Jan, 2021; 7(1): 1-6

Tool in Molecular Biology and Biological Activities of Cyclotides with Particular Emphasizes at Molecular Level.

23. Dodeigne, C., Thunus, L., \& Lejeune, R. (2000). Chemiluminescence as diagnostic tool. A review. Talanta, 51(3), 415-439.

24. Shafiq, S., Adeel, M., Raza, H., Iqbal, R., Ahmad, Z., Naeem, M., ... \& Azmi, U. R. (2019). Effects of Foliar Application of Selenium in Maize (Zea Mays L.) under Cadmium Toxicity. In Biological Forum-An International Journal (Vol. 11, No. 2, pp. 27-37).

25. Naeem, M., Hayat, M., Qamar, S. A., Mehmood, T., Munir, A., Ahmad, G., ... \& Hussain, A. (2019). Risk factors, genetic mutations and prevention of breast cancer. Int. J. Biosci, 14(4), 492-496.

26. Morris, C. R., Kato, G. J., Poljakovic, M., Wang, X., Blackwelder, W. C., Sachdev, V., ... \& Gladwin, M. T. (2005). Dysregulated arginine metabolism, hemolysis-associated pulmonary hypertension, and mortality in sickle cell disease. Jama, 294(1), 81-90.

27. Kato, G. J., Gladwin, M. T., \& Steinberg, M. H. (2007). Deconstructing sickle cell disease: reappraisal of the role of hemolysis in the development of clinical subphenotypes. Blood reviews, 21(1), 37-47.

28. Al-Alaq, F. T., Abdulazeem, L., Al-Dahmoshi, H. O. M., Al-Khafaji, N. S., \& Al-Wesawei, Y. A. (2016). PCR-based investigation of oxygenase among crude oil degrading bacteria in Hilla city, Iraq. International Journal of Pharm Tech Research, 9(5), 284-291.

29. Du, H., Wang, Y., Yao, X., Luo, Q., Zhu, W., Li, X., \& Shen, Z. (2016). Injectable cationic hydrogels with high antibacterial activity and low toxicity. Polymer Chemistry, 7(36), 5620-5624.
30. Fujita, T., Horiuchi, A., Ogawa, M., Yoshida, H., Hirose, Y., Nagano, N., \& Takahashi, T. (2017). Genetic diversity in Streptococcus dysgalactiae subsp. equisimilis isolates from patients with invasive and noninvasive infections in a Japanese university hospital (2014-2015). Japanese Journal of Infectious Diseases, 70(1), 100-104.

31. Aldahoun, M. A. A., Jaafar, M. S., Al-Akhras, M. A. H., \& Bououdina, M. (2017). Enhanced nanocurcumin toxicity against (PC3) tumor and microbial by using magnetic field in vitro. Artificial cells, nanomedicine, and biotechnology, 45(4), 843-853.

32. Desouky, S. E., Hassan, S. E., El-gamal, M. S., Ragab, M. A. E. T. I., \& Emam, M. (2017). Effect Of Salvia Egypticae And Foeniculum Vulgara Extracts On Quorum Sensing And Biofilm Formation Of Methicillin Resistant/Sensitive Staphylococcus Aureus Isolates. World journal of pharmaceutical And medical research, 3, 466-475.

33. Yanti, N. L. M. S., Suardana, I. W., \& Suarjana, I. G. K. (2019). Hemolytical Profile Of Streptococcus Spfrom Nasal Swab Isolation At Traditional Farm In Bongkasa Village, Abiansemal Subdistrict, Badung Regency, Bali. Journal of Veterinary and Animal Sciences pISSN, 2(2), 52-57.

34. Al-Qurashi, F. M. S., \& Kadhum, Z. I. A. (2019). Antibacterial Effect of some Herbal plants against Pathogenic Bacteria Isolated from Patients with Urinary Tract Infections (UTI). AL-yarmouk Journall, 11(1), 36-47.

35. Turista, D. D. R. (2020). Plagiarisme Checker_The growth of Staphylococcus aureus.

36. Hazafa, A., Batool, A., Ahmad, S., Amjad, M., Chaudhry, S. N., Asad, J., ... \& Ghani, U. (2020). Humanin: A mitochondrial-derived peptide in the treatment of apoptosis-related diseases. Life Sciences, 118679 